\title{
Immature Granulocyte Count
}

National Cancer Institute

\section{Source}

National Cancer Institute. Immature Granulocyte Count. NCI Thesaurus. Code C96675.

The determination of the amount of immature granulocytes present in a sample. 